\title{
Imágenes que hablan: el túmulo de Felipe IV en Pamplona
}

\author{
Speaking Images: the catafalque of Philip IV in \\ Pamplona
}

\author{
María Adelaida ALLO MANERO \\ Universidad de Zaragoza
}

Resumen: El Departamento de Estampas y Dibujos del British Museum conserva la estampa anónima de un túmulo real para cuya catalogación ha establecido una cronología en torno a 1650 y una filiación artística perteneciente a la escuela francesa.

El presente estudio aporta un análisis arquitectónico e iconográfico de la obra e identifica la estampa con el túmulo construido en Pamplona en 1665 para conmemorar las exequias reales del monarca español Felipe IV. Asimismo se ofrece una hipótesis razonada sobre la función y destino que tuvo esta estampa, que contribuye a poner de relieve su destacado valor documental.

Palabras clave: Navarra, Casa de Austria, exequias reales, Felipe IV, túmulo, libro español de exequias.

Abstract: The Department of Prints and Drawings of the British Museum preserves the anonymous print of a royal catafalque in which cataloging has established a timeline around 1650 and an artistic relationship belonging to the French school. The present study provides an architectural and iconographic analysis of this artistic work and identifies the print with the catafalque built in Pamplona in 1665 to commemorate the royal funeral of Spanish King Philip IV. It is also offered a reasoned hypotheses about the function this print had, wich helps highlighting its outstanding documentary value.

Key words: Navarra, House of Habsburg, royal obsequies, Philip IV, catafalque, spanish funeral booklet.

Los estudios realizados sobre las exequias reales de los monarcas españoles durante el Antiguo Régimen han conseguido configurar con el tiempo un importante corpus de arte gráfico nutrido, básicamente, a partir de las estampas que ilustraron las relaciones impresas sobre dichas ceremonias. Junto a frontispicios alegóricos, túmulos y plantas de templos con organigramas de colocación de asistentes, jeroglíficos y juegos e ingenios literarios y matemáticos, contamos también, aunque en menor número, con un interesante 
conjunto de esbozos y dibujos preparatorios, trazas arquitectónicas, e incluso con algunas representaciones pictóricas originales de lienzos y jeroglíficos que formaron parte de aquellos extraordinarios aparatos fúnebres.

No obstante, a pesar de la riqueza e importancia artística que ha ido adquiriendo este abultado corpus, parece que todavía resulta válida la afirmación de que el libro de exequias reales ilustrado fue totalmente excepcional, al menos en los diferentes reinos peninsulares, y que la razón más convincente que lo justifica no es tanto la ausencia de una buena escuela de grabadores hispanos, cuanto el elevado valor económico que alcanzó el grabado en la península durante la segunda mitad del siglo XVI y durante todo el siglo XVII. En el análisis realizado en su día sobre la producción editorial del libro de exequias reales en España se llegaba a la conclusión, sobre este respecto, que el coste económico de un libro ilustrado podía situarse en torno al doble o incluso al triple, dependiendo del número de estampas, del correspondiente a las relaciones no ilustradas ${ }^{1}$.

Y si excepcional fue aprobar el cometido de estas empresas editoriales por parte de las instituciones patrocinadoras, también hay que juzgar de extraordinaria su voluntad por afrontar de manera sistemática la publicación de una relación oficial de la ceremonia, incluso no ilustrada, no tratándose en consecuencia de una actividad tan ordinaria como podría pensarse aparentemente. Tan sólo la Corte y la ciudad de Zaragoza cuentan con una actividad seriada en la publicación de todas las exequias reales celebradas en el periodo entre 1558 y $1700^{2}$.

En consecuencia, si los patrocinadores de estas ceremonias percibían la publicación de los actos como una carga onerosa tanto más difícil de satisfacer si iba acompañada de imágenes, ¿por qué las abordaron?, ¿qué función desempeñaron?, ¿cuál es su nivel

\footnotetext{
${ }^{1}$ M.A. ALLO MANERO, Exequias de la Casa de Austria en España, Italia e Hispanoamérica, Zaragoza, 1992, p. 70

${ }^{2}$ Ibídem, p. 68
}

de fiabilidad respecto a las obras finalmente ejecutadas?, ¿a quién o a quiénes estuvieron dirigidas?, ¿por qué una ciudad concreta inicia esta actividad y a partir de un momento dado la detiene?, o al contrario, ¿por qué una ciudad o una determinada institución decide en un momento puntual una empresa de esta índole?, en suma, ¿cómo poner en valor este tipo de fuentes históricas?.

Ciertamente son muchas las preguntas $\mathrm{y}$, desgraciadamente, contamos todavía con pocas respuestas fiables. Por lo tanto, lejos de suscitar una controversia en torno al valor cultural de este género de relaciones y de imágenes, mi intención en estos momentos no es otra que contribuir a este interesantísimo debate a través del análisis de una curiosa estampa que, además de ser desconocida hasta la fecha, proporciona respuestas de interés en torno a la precisión y grado de exigencia requeridos en la época a las ilustraciones. La propuesta de identificación que se hace la sitúa en las exequias reales de Felipe IV, que como es bien sabido constituye la ceremonia luctuosa mejor conocida de toda la Casa de Austria, pues fueron numerosas las ciudades de la Monarquía Hispana que determinaron comunicar y perpetuar la memoria de unos actos que contaban con una tradición ya muy establecida.

En consecuencia, no sólo se trata de un túmulo más para nuestro corpus de arte efímero; la pertinencia de una correcta identificación basada en una ajustada valoración artística e iconográfica esclarecerá las bases para proponer una hipótesis razonada sobre los porqués de su edición, desvelando su destacado valor histórico.

\section{LA NUEVA ESTAMPA}

El Departamento de Estampas y Dibujos del British Museum conserva en su extraordinaria y riquísima colección de arte gráfico cifrada en torno a dos millones de estampas y 50.000 dibujos- la estampa de un catafalco real (1869.0410.690) que ha sido objeto de nuestro interés y sobre el que deseamos centrar nuestra atención en estos momentos (Fig. 1). Las opciones de trabajo que ofrecen las nuevas 
tecnologías nos permitieron localizarla gracias a su creación como recurso digital y el consiguiente lanzamiento a la magnífica base de datos que el museo británico ha decidido disponer al servicio de los investigadores vía web. Esta circunstancia ha posibilitado su estudio y ha servido para proponer una identificación distinta a la sugerida por el Museo.

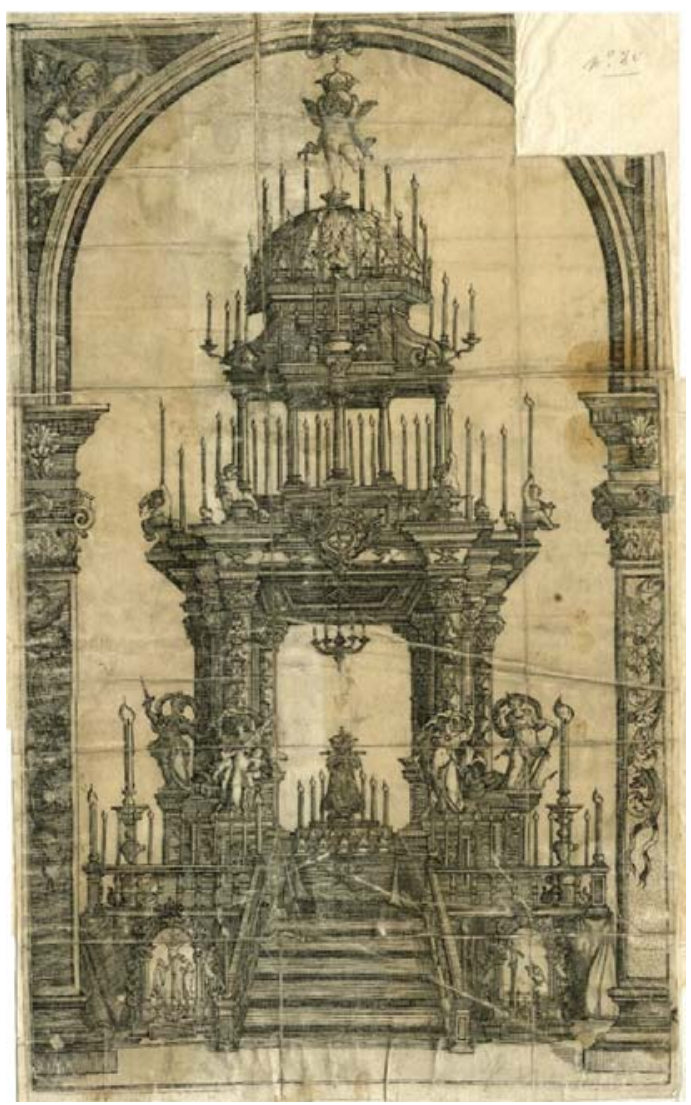

- Fig. 1. Túmulo de Felipe IV en Pamplona. Londres, British Museum. (OThe Trustees of the British Museum.

La catalogación de esta estampa, también accesible vía web, incluye una exhaustiva información alusiva a su procedencia e ingreso en la colección, una puntual descripción física y técnica, y finalmente una propuesta de identificación en la que se propone cronología y filiación artística, habida cuenta que la estampa adolece de firma o de cualquier tipo de inscripción alusiva ${ }^{3}$.

${ }^{3}$ En la pantalla de visualización puede observarse que el Museo Británico ya ha añadido la posible filia-
Gracias a esta información se sabe que la estampa forma parte de las colecciones del British Museum desde 1869, fecha en la que ingresó dentro de un lote de 2618 grabados subastados en Sotheby's procedentes de la colección del político, financiero y pionero en el desarrollo del ferrocarril en España, José de Salamanca y Mayol, más conocido como Marqués de Salamanca. Colección, no obstante, que tras los estudios de Jesusa Vega sabemos que fue realizada por el pintor, grabador y litógrafo José de Madrazo, asimismo fundador y director del Real Establecimiento Litográfico y director del Museo de Madrid, actual Museo del Prado, y que tras su muerte, fue adquirida por el Marqués de Salamanca ${ }^{4}$.

La descripción física y técnica confirma que se trata de una estampa calcográfica -cobre en talla dulce- y que sus dimensiones actuales - $439 \times 265 \mathrm{~mm}$ - no son las originales, pues ha sido severamente recortada y pegada a un segundo soporte, sin duda por su mal estado de conservación. Su observación además nos permite añadir que la estampa se encuentra incompleta, pues ofrece un área perdida importante en su esquina superior derecha, dejando ver en el papel que le sirve de soporte una anotación manuscrita hecha con grafito en la que se puede leer “No. 20".

Finalmente, y como se trata de una estampa anónima, el Museo la catalogó atribuyéndole una cronología en torno a 1650 y una filiación artística perteneciente a la escuela francesa.

ción española de esta estampa < http://www.britishmuseum.org/research/collection_online/collection_object_ details.aspx?objectId=3236540\&partId=1>. No obstante, todavía mantiene la atribución a la escuela francesa en la información primitiva del recurso digital: <http://collection.britishmuseum.org/id/object/PPA253611>.

Quizás por esta razón la estampa no figuró en el magnífico catálogo sobre las colecciones de estampas y dibujos españoles conservados en el British Museum de M. Mc DONALD, Renaissance to Goya: prints and drawings made in Spain, Londres, 2012.

${ }^{4}$ J. VEGA, Origen de la litografía en España: El Real Establecimiento Litográfico, Madrid, 1990. 


\section{ANÁLISIS E IDENTIFICACIÓN DE LA ESTAMPA}

La observación de la estampa rápidamente nos traslada a la producción de túmulos realizados en Navarra y más concretamente a los erigidos en Pamplona, debido no solamente al escudo de armas que figura en el centro del entablamento del primer cuerpo, sino también a toda una serie de rasgos distintivos que llegaron a caracterizar a los túmulos erigidos para solemnizar las exequias reales del Consejo Real de Navarra y del regimiento pamplonés, y que pueden ser perfectamente observados en la ya conocida estampa del túmulo de Mariana de Austria de 1696 (Fig. 2).

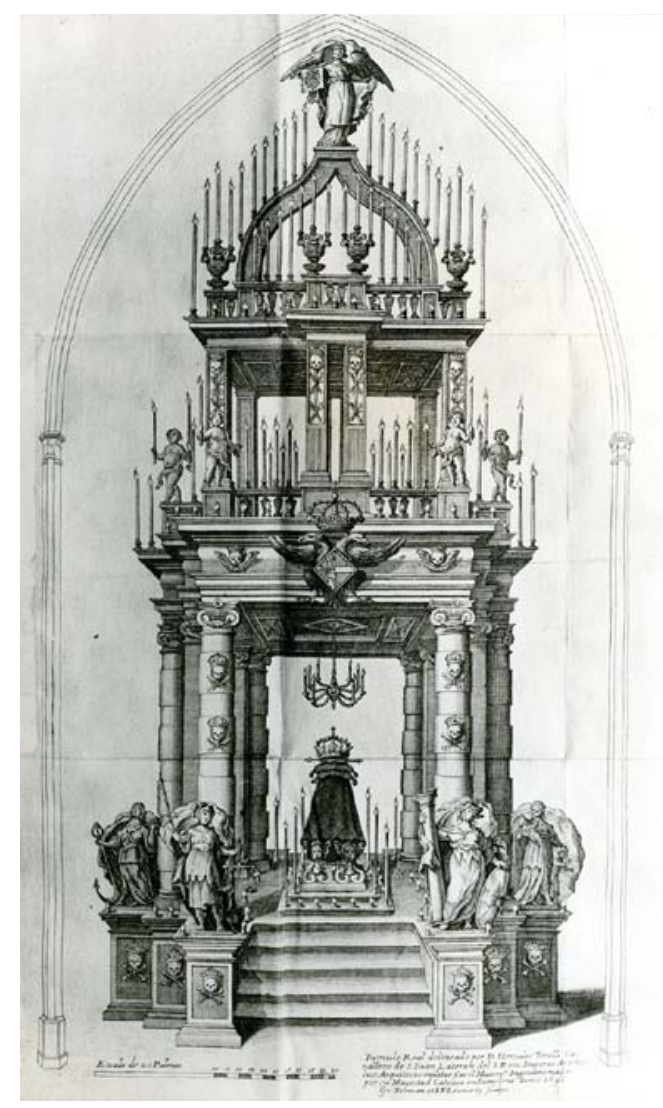

- Fig. 2. Túmulo de Mariana de Austria en Pamplona. Madrid, Biblioteca Nacional

Como se puede comprobar, el escudo corresponde a las armas del Reino de Navarra y por ello presenta las conocidas cadenas de oro dispuestas en orla y cruz, faltando no obstante las correspondientes al sotuer.
En cualquier caso, el grabador no olvidó la inclusión de la esmeralda en el corazón o abismo. El escudo, siguiendo la costumbre, aparece timbrado con una corona real abierta rematada con orbe cruzado en su cima.

Que además de tratarse de un túmulo navarro está dedicado a un rey, nos lo indican las insignias reales colocadas sobre la doble almohada que remata la urna funeraria así como su especial disposición: una gran corona real y un cetro atravesándola, confirmando de esta manera la información proporcionada en 1819 por Francisco Cruz de Aramburu a la hora de esclarecer el adorno de la urna cuando se armaba el túmulo en la catedral de Pamplona:

"se pone la corona y el cetro trabesado por ella quando es Rey a quien se celebran las exequias, y si fuera Reina tan solo la corona" ${ }^{\prime \prime}$.

Si se establece una comparación formal entre nuestra estampa anónima y la de del túmulo pamplonés de 1696 se aprecian inmediatamente toda una serie de similitudes harto evidentes.

En primer lugar, podemos constatar una composición general idéntica en ambas estampas, que lleva a representar el alzado del túmulo desde el mismo punto de perspectiva y bajo un arco apoyado sobre pilares, sin duda con objeto de sugerir la monumentalidad de la obra, próxima a la bóveda del templo.

En segundo lugar, llaman poderosamente la atención las cuatro esculturas alegóricas sobre pedestales del primer cuerpo: Justicia, Caridad, Fe y Esperanza en nuestra estampa; Esperanza, Justicia, Fortaleza y Caridad en 1696. Su similitud no sólo se apoya en la identidad de sus codificados atributos, sino que alcanza a la propia representación pictórica de las imágenes.

En tercer lugar, el adorno de la techumbre del primer cuerpo, que en ambos casos aparece constituido por un marcado

${ }^{5}$ Cita recogida en el estudio sobre las exequias reales del regimiento pamplonés de J. J. AZANZA y J. L. MOLINS, Exequias reales del regimiento pamplonés en la Edad Moderna, Pamplona, 2005, p. 91. 
artesonado de cuyo centro queda suspendida una lámpara de idéntico diseño.

En cuarto lugar, la iluminación dispuesta en torno a la urna funeraria, circundada por pequeñas lámparas o "bujías" y elevadas hachas en las esquinas del estrado.

En quinto lugar, el conjunto de angelotes portadores de hachas de luminaria colocados en el segundo cuerpo de ambos túmulos.

Y en sexto y último lugar, los dos altares portátiles adornados con ricas pinturas flanqueando la escalinata de acceso $^{6}$, presentes en la estampa anónima y, aunque no representados en la de 1696, existentes en la obra finalmente ejecutada, tal y como confirma el autor del libro de exequias de Mariana de Austria, Juan López de Cuellar ${ }^{7}$. Esta última coincidencia resulta harto reveladora, puesto que su presencia en los túmulos pamploneses está documentada desde $1598^{\circ}$, tratándose en consecuencia de la prueba más consistente para establecer un nexo certero entre la estampa y los túmulos construidos en la catedral de Pamplona.

No obstante, las puntuales analogías enumeradas no terminan aquí y se tornan todavía más concluyentes si se examinan con atención los principales rasgos distintivos de la estructura arquitectónica que ofrece el túmulo de $1696^{9}$, presentes asimismo

\footnotetext{
${ }^{6}$ En el lienzo del altar dispuesto en el lado izquierdo figura una Crucifixión, con Cristo en la cruz y la Virgen y san Juan a los pies, mientras que en el lienzo del altar derecho aparece, probablemente, san Francisco de Asís a los pies de Cristo en la cruz.

${ }^{7}$ J. LÓPEZ DE CUELLAR, Batallas y Triumphos de la Serenísima Señora Doña Mariana de Austria Reyna Madre de España Nuestra Señora. En la Pompa Funeral que el día diez y ocho de junio celebraron los Tribunales Reales de Navarra, siendo Virrey y Capitán General el Excelentísimo Señor Don Baltasar de Zúñiga, Gentil-Hombre de la Cámara del Rey Nuestro Señor. Dedícalos a su Excelencia el licenciado... del Consejo de su Majestad y su oidor más antiguo en el Real y Supremo de este Reyno, Pamplona, (s. a.), pp. 86-88.

${ }^{8}$ R. FERNÁNDEZ GRACIA, “El túmulo de Felipe II en la catedral de Pamplona", en Actas del Congreso Internacional Felipe II y las Artes, Madrid, 2000, pp. 453-464.

${ }^{9}$ M. A. ALLO MANERO, Op. cit., pp. 687-689.
}

en el catafalco anónimo aunque formulados con un lenguaje ornamental distinto.

Efectivamente, si se analizan ambas estructuras desde un punto de vista tipológi$\mathrm{co}$, seguimos observando en los dos casos un túmulo formado por la superposición de dos cuerpos arquitectónicos bien definidos y con una independencia estructural totalmente delimitada, formados por el mismo número, tipo y disposición en planta de sus soportes, e incluso, al menos en apariencia, con un sistema compositivo muy similar. Las diferencias más apreciables se sitúan en el sistema de cubierta y en la selección del orden: mientras que 1696 se apostó por la cúpula de nervios y un libresco orden jónico, en el túmulo anónimo se observa el empleo de la media naranja apoyada sobre destacado basamento y el gusto por el orden compuesto, acompañados de ornamentación característica de mediados del siglo XVII.

Así pues, todos los argumentos expuestos hasta el momento nos ayudan a concluir que la estampa representa el túmulo erigido en la catedral de Pamplona para las exequias reales del rey Felipe IV, sobre las cuáles y hasta el momento sólo se tenía noticia de que "el catafalco se levantó en medio de la nave de la Iglesia Catedral, entre el altar mayor y coro della, como se acostumbra a hacer en los funerales"10.

Aceptada la identificación que acabamos de proponer, rápidamente se desprenden dos conclusiones importantes.

La primera revela que el túmulo construido en Pamplona para honrar las exequias reales de Felipe IV se encuentra en total sintonía con las peculiaridades más representativas que fueron propuestas en su día para definir el túmulo barroco español en el periodo 1644$1665^{11}$. Y en este sentido la estructura arquitectónica del túmulo pamplonés, al igual que las

${ }^{10}$ Texto recogido del estudio de J. J. AZANZA y J. L. MOLINS, Op. cit., p. 89. También confirman el pago de 300 reales al maestro carpintero Pedro de Aldaz y Arbella en concepto de armar la antigua estructura del catafalco conservado en dependencias municipales. Ibídem, p. 96.

${ }^{11}$ M. A. ALLO MANERO, Op. cit., pp. 96-97. 
de los construidos en este periodo, presenta una formulación clasicista muy dependiente de la etapa anterior, aunque ahora ejecutada con un lenguaje arquitectónico renovado. Los órdenes clásicos quedan metamorfoseados por un código ornamental ajeno a su ejecución clásica y se difunde, como lo demuestra nuestro caso, el uso del sexto orden creado por el hermano jesuita Francisco Bautista y el quebramiento sin excesos de los entablamentos. Desaparece la superposición de los órdenes clásicos, pero persiste de forma muy generalizada la presencia de la cúpula como sistema de cubierta del último cuerpo. El repertorio ornamental adquiere potente volumetría para reforzar el claroscuro e invade todas las partes de la estructura arquitectónica; la carnosa hojarasca, que se observa en la media naranja de nuestro túmulo, o los característicos aletones que a manera de arbotantes flanquean basamentos o macizos, y que también aparecen en Pamplona, constituyen motivos de fecunda repercusión en otros túmulos peninsulares erigidos en honor de Felipe IV.

La segunda conclusión que se desprende de esta identificación permite reforzar la hipótesis planteada por J. J. Azanza y J. L. Molins, quienes tras el minucioso análisis de la documentación conservada en el archivo municipal de Pamplona en torno a las exequias reales organizadas por el regimiento de la ciudad, concluyen en una probable reutilización del mismo catafalco en las sucesivas exequias reales celebradas en el periodo 1598$1742^{12}$. La existencia de una crónica descriptiva sobre el catafalco erigido a Felipe II permite tener conocimiento sobre las peculiaridades arquitectónicas de la estructura vignolesca de nueva planta que trazó Domingo de Bidarte para la ocasión. Dichas peculiaridades parecen estar presentes todavía en una descripción genérica relativa a las piezas que componían el catafalco de las exequias celebradas en

${ }^{12}$ J. J. AZANZA y J. L. MOLINS, Op. cit., pp. 92-100. El estudio del sistema organizativo de la ceremonia en este periodo permite saber que en Pamplona fue empleado el mismo túmulo en las funciones del Consejo Real y en las del Regimiento de la ciudad, si bien la responsabilidad de su construcción y colocación recayó en el Regimiento.
1644 y 1646, las cuáles se vuelven a repetir en el construido en 1696, razón que justificaría el carácter retardatario de la estructura para estas fechas. El nexo de unión lo constituiría lógicamente el túmulo de Felipe IV, en el que como se ha tenido ocasión de comprobar, reaparecen efectivamente estas peculiaridades distintivas del catafalco pamplonés realizado a lo largo de todo el siglo XVII.

\section{ESTUDIO Y VALORACIÓN HISTÓRICA}

Pudiera parecer a simple vista que el proceso de identificación realizado a nuestra estampa agota todo su valor informativo, es decir, que una vez concretado que se trata del túmulo de Felipe IV en Pamplona, nada resta por añadir. Pero la realidad es muy distinta si nos interrogamos por su destino, por su función: ¿para qué se hizo esta magnífica ilustración?.

\section{Cualquier especialista en Arte Efímero} sabría reconocer que nos encontramos frente a la estampa que habría de ilustrar un libro oficial de exequias reales y, en consecuencia, su existencia confirma cuanto menos que hubo intención de abordar el proyecto. Esta certeza cobra aún más verosimilitud si se considera que el entonces Virrey de Navarra era D. Francisco Tuttavilla y del Rufo, duque de San Germán, destacado militar napolitano cuya actuación como capitán general de Extremadura contra la rebelión independentista portuguesa de los años cuarenta, le procuró una importante carrera política durante el reinado de Felipe IV. Por lo tanto, la tradición de una relación impresa y además ilustrada sobre las exequias reales navarras arrancaría, en principio, de 1665. No obstante, ¿existe este libro de exequias?.

El meritorio trabajo de Antonio Pérez Goyena permitió esclarecer la existencia de un breve impreso realizado en Pamplona en 1666 por el impresor del Reino, Gaspar Martínez, sobre las exequias reales organizadas por el Consejo Real de Navarra en honor de Felipe 
$\mathrm{IV}^{13}$, que aparentemente podría hacernos pensar que fue el destinatario de nuestra estampa. En la actualidad se trata de un ejemplar raro ${ }^{14}$, quizás debido a su condición de edición no venal, es decir, fuera de comercio, dado que la obra adolece de las habituales páginas de preliminares. Pero, ¿puede ser asociado ciertamente con la estampa del túmulo de Felipe IV en Pamplona?. El examen de las afirmaciones vertidas por su autor en la escueta Introducción de la obra y la iconografía de su portada permiten responder al interrogante.

En efecto, el autor, Joaquín Francisco Aguirre y Álava, afirma que el Virrey ordenó disponer las honras con toda la pompa funeral acostumbrada por el Consejo Real de Navarra, encargando las prevenciones relacionadas con el túmulo al decano de dicha institución, D. Juan de Aguirre, su padre. Tras aludir a la grandeza que ostentó el aparato fúnebre construido y precisar que "no me toca a mí el decirlo", el autor afirma que se adornó con muchas poesías y que “juzgó haría servicio a todos si recogidas las diesse a la estampa con la oración fúnebre que dixo el padre Juan García Marín, de la Compañía de Jesús y confesor de V. Exc. Y tomada esta resolución no tuve razón de dudar que todo lo devía poner a la protección de V. Exc., a quien se deve la disposición de todo".

Todos estos extremos aparecen confirmados en la tosca portada del libro, compuesta y grabada por un grabador del que

${ }^{13}$ A. PÉREZ GOYENA, Ensayo de bibliografía navarra desde la creación de la imprenta en Pamplona hasta el año 1910, Pamplona, 1947-1962, t. II, no 626: J. de AGUIRRE Y ALAVA, Honores fúnebres que hizo el Real Consexo de Navarra a la piadosa memoria del Rey N. S. Philippo IV el Grande. Dedícalos al Exc‥ S. Duque de S. Germán, Virey y Capitán General de Navarra y Guipúzcoa D. Ioachin Fro de Aguirre y Álava, Caballero de la Orden de Santiago, Colegial Mayor de Santa Cruz, Pamplona, 1666.

${ }^{14}$ El Catálogo Colectivo de Patrimonio Bibliográfico Español consigna la existencia de tres ejemplares de este impreso, dos en la Biblioteca Nacional y uno en la Biblioteca de Castilla-La Mancha; se conserva otro más en la Hispanic Society en New York. sólo se conoce esta obra: "Nosela inv. et f." ${ }^{15}$, y en la que se contó posiblemente con la asesoría del propio autor. Como se puede observar se trata de una portada heráldica con el escudo del Virrey, D. Francisco Tutavilla y del Rufo Duque de San Germán, en la parte superior y otros dos escudos más, quizás relacionados con el autor, futuro I Conde de Ayanz, flanqueando el título de la obra. La parte inferior muestra una esquemática vista de la ciudad dentro de su fortificación con un personaje tocando el laúd y la leyenda "Fortia Suaviter", es decir, suavemente en el modo y fuertemente en la $\operatorname{cosa}^{16}$, aludiendo sin duda al delicado empeño que tuvo el autor para sacar adelante esta obra (Fig. 3).

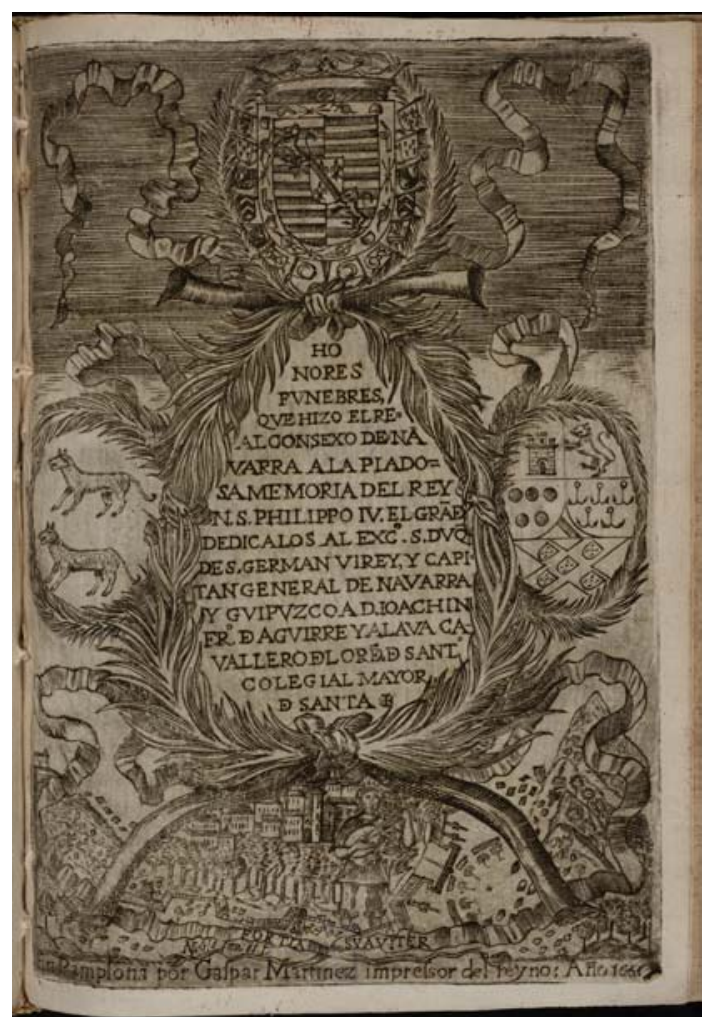

- Fig. 3. Portada de J. de Aguirre y Álava, Honras fúnebres.... Madrid, Biblioteca Nacional

${ }^{15}$ E. PÁEZ RIOS, Repertorio de grabados españoles, Madrid, 1981, t. II, no 1510 . Sugiere la posibilidad de que se trate de Noseras, registrado en los trabajos de J. Caveda.

${ }^{16}$ Se trata de una locución latina de Marco Favio Quintiliano, quien la da como norma de éxito, pues indica la conveniencia de conciliar la energía con la suavidad en la gestión de los asuntos. Fue muy utilizada en el ámbito jurídico. 
Por lo tanto nos encontramos frente a un tipo de impreso, por otra parte común en muchas ciudades españolas, que sirvió solamente para recoger las composiciones literarias realizadas para la ocasión y la oración fúnebre pronunciada en la ceremonia. Pero sin duda no se trata del libro oficial de las exequias de Felipe IV, habida cuenta que en estas fechas las relaciones de exequias reales, como género, estaban totalmente configuradas tanto en sus distintas partes como en sus contenidos. Y aún considerando la posibilidad de encontrarnos ante una relación totalmente atípica, la inclusión de una estampa entre los cuadernillos siempre habría dejado una huella material, que sin embargo no existe en ninguno de los ejemplares conservados. En consecuencia, nuestra estampa no se puede relacionar con este impreso.

Así pues, si el impreso analizado no fue el libro oficial de exequias y los especialistas en bibliografía navarra no han proporcionado todavía noticias al respecto, podemos suponer que, probablemente, dicha obra nunca vio la luz.

Interrogarnos hoy sobre las razones que motivaron el abandono del proyecto original sin apoyaturas documentales puede resultar arriesgado, pero consideramos que el examen de algunos aspectos relacionados con la propia estampa puede proporcionar respuestas razonables al respecto.

En primer lugar llama poderosamente la atención que la estampa sea anónima, que no posea firma alguna relativa al grabador que la hizo, situación completamente ajena a cualquiera de los grabados en talla dulce totalmente concluidos que se conocen de estas fechas y que por lo tanto sólo se justificaría si se considera como una prueba.

En segundo lugar se observa una técnica cuidada, formalmente próxima a muchos de los grabados coetáneos de la escuela madrileña ${ }^{17}$; el tratamiento de las figuras

\footnotetext{
${ }^{17}$ El examen de la filigrana del papel podría complementar este extremo, pero no ha sido posible su realización por el delicado estado de conservación que
}

alegóricas, el marco arquitectónico con los angelotes e incluso la representación de éstos últimos recuerdan estampas de Gregorio Fosman y Medina o incluso de Pedro de Villafranca.

$\mathrm{Y}$ en tercer lugar, y tras los estudios realizados sobre la imprenta navarra y los libros ilustrados coetáneos a la estampa, hay que reconocer cuán ajeno resulta este grabado calcográfico en la Pamplona de mediados del siglo XVII. Como ya ha sido puesto en evidencia, dentro de la mediocre producción libraria que se llevó a cabo en la ciudad, sólo destacaron contadas ediciones, promovidas bien por órdenes religiosas o por el propio Consejo del Reino. Para resolver con garantía estos encargos se recurrió de forma más o menos generalizada a prestigiosos profesionales del grabado, casi siempre foráneos, entre ellos el propio Fosman, que colaboró en distintas ocasiones en este periodo ${ }^{18}$.

Teniendo presente estas tres circunstancias y considerando el procedimiento habitual de encargo y edición de otros libros similares en esta época, se puede ofrecer finalmente una hipótesis razonada sobre la fallida edición del que hubiera podido ser el primer libro de exequias reales de Pamplona.

En efecto, no resulta improbable pensar que, ante el deseo del Virrey y del Real Consejo de abordar una relación ilustrada, el diputado o comisario nombrado para el efecto recurriera a un grabador de reconocido prestigio, muy probablemente madrileño, a quien naturalmente le proporcionaron un dibujo del túmulo construido. Tal supuesto sustentaría la consideración de prueba de nuestra estampa, la cuál tendría que ser presentada y aprobada antes de la tirada final y tras cuyo visto bueno, el grabador procedepresenta la estampa, lo que nos comunicó amablemente
su responsable, el conservador Mark Mc Donald.

${ }^{18}$ C. RODRÍGUEZ PELÁEZ, "El grabado barroco en los impresos vasco-navarros", Ondare: Cuadernos de artes plásticas y monumentales, nำ19, 2000, pp. 151-182 y J. ITÚRBIDE DÍAZ, Escribir e imprimir. El libro en el Reino de Navarra en el siglo XVIII, Pamplona, 2007. 
ría a firmar convenientemente la plancha o matriz de cobre. No obstante y a pesar de la calidad técnica conseguida, la estampa presentó un problema, sin duda determinante en la época, que se centraba en la incorrecta representación del escudo de armas del Reino de Navarra, ocasionando a buen seguro su desautorización.

Fuera o no ésta la única razón para abandonar el proyecto original es una incóg- nita que sólo podrá desvelar la documentación sobre el asunto, pero lo cierto es que la situación pudo motivar lo suficiente a D. Joaquín Aguirre y Álava, destacado procurador a quien le quedaba por delante una rápida y fecunda vida política, para impulsar una edición distinta que perpetuara la memoria de las exequias organizadas por el Consejo Real a Felipe IV y que, como no podía ser de otro modo, dedicó al Virrey. 